\title{
COMMENTARY
}

\section{Unplanned extubation in the ICU: a marker of quality assurance of mechanical ventilation}

\author{
Óscar Peñuelas, ${ }^{1,2}$, Fernando Frutos-Vivar ${ }^{1,2}$ and Andrés Esteban*1,2 \\ See related research by de Groot et al., http://ccforum.com/content/15/1/R19
}

\begin{abstract}
One of the most frequent complications associated with endotracheal intubation itself in intensive care units is unplanned extubation, which represents a potentially serious complication given that many patients may need reintubation while in poor condition. This scenario may account for an increase in morbidity and even in mortality. To be able to compare the rates of unplanned extubation in clinical practice, unplanned extubation should be expressed as incidence density of days at risk. Also, this complication (unplanned extubation and reintubation rates) may be used as a marker of quality of weaning care in intensive care units.
\end{abstract}

In the previous issue of Critical Care, de Groot and colleagues [1] reported a prospective case control study in which an unplanned extubation occurred in $2 \%$ of mechanically ventilated patients. Additionally, in a multivariable analysis, the authors reported risk factors for this event and found a significantly lower hospital mortality for patients with unplanned extubation than for those without it.

Unplanned extubation is a major complication of translaryngeal intubation in patients with mechanical ventilation and occurs in $3 \%$ to $16 \%$ of mechanically ventilated patients [2,3]. Other authors [4,5] have reported a lower frequency of unplanned extubation in comparison with previous studies.

One explanation could be that the calculation for the frequency of unplanned extubation takes the number of intubated patients, but not the days at risk (days with a

\footnotetext{
*Correspondence: aesteban@ucigetafe.com

IIntensive Care Unit, Hospital Universitario de Getafe, Carretera de Toledo,

km 12500, Getafe, 28905 Madrid, Spain

Full list of author information is available at the end of the article
}

tube in place), as the denominator, so it is difficult to compare populations in which the duration of intubation is unavoidably different [6]. Therefore, the rates should be expressed as incidence density because the time that patients are followed may differ from one study to another. In this study, the incidence density is mentioned, making it possible to compare the results of the study with those of other studies.

Understanding the factors associated with unplanned extubation is crucial for identifying patients at risk of this complication and thus for developing interventions to reduce the frequency of this complication. Some aspects such as nurse workload and standardization of procedures such as the method of securing the endotracheal tube and the use of hand restraints have been reported to be useful in reducing the removal of the orotracheal tube [7]. In this sense, this study gives novel information about other factors independently associated with unplanned extubation, such as the level of sedation according to the Ramsay scale and the use of midazolam. On the other hand, the establishment of measures to prevent the problem of unplanned extubation can help to decrease unplanned extubation rates. Detecting short displacements, correcting orotracheal tube position at the teeth at least once per shift, and keeping patients' hands more than $20 \mathrm{~cm}$ away from the endotracheal tube have been shown to be useful in decreasing unplanned extubation [8]. All of these strategies point out the importance of the implementation of nurse and physician education as a policy of quality care in intensive care units (ICUs).

Between $30 \%$ and $70 \%$ of unplanned extubations do not result in reintubation [9]. de Groot and colleagues found that $53 \%$ of unplanned extubations were successfully tolerated. This observation is consistent with the hypothesis that physicians have difficulty in judging when patients can be liberated from mechanical ventilation. Betbese and colleagues [10] related the need of reintubation after an episode of unplanned extubation to whether or not the patient is in the weaning phase of mechanical ventilation. Patients presenting unplanned extubation during weaning required significantly fewer 
reintubations, whereas reintubation was mandatory in $81.5 \%$ of patients under full mechanical ventilation support. In view of these observations, it is conceivable that the process of weaning may be longer than necessary in some patients. In this way, unplanned extubation rates may be used as a marker of evaluation and an indicator for quality control of care.

This complication itself has been not associated with an increase in mortality of ICU patients in comparison with that of matched controls [11]. However, some studies have shown higher ICU and hospital mortality for patients who failed to tolerate an unplanned extubation and require reintubation. The failed group also has a longer duration of mechanical ventilation and longer ICU and hospital stays, possibly because these patients had not yet sufficiently recovered from their acute illness to begin weaning trials. Rapid reinstitution of ventilator support and control of the airway of patients who failed unplanned extubation may prevent the development of complications and could contribute to decreased mortality [12]. In the study by de Groot and colleagues, $89 \%$ of the patients who had to be reintubated were reintubated within 1 hour of the unplanned extubation and this could explain the lower hospital mortality in comparison with patients without unplanned extubation.

In conclusion, the identification of risk factors for unplanned extubation may be useful in reducing it. The unplanned extubation and eventual reintubation rates should be implemented as a program of quality assurance in ICUs.

Abbreviation

ICU, intensive care unit.

Competing interests

The authors declare that they have no competing interests.

\section{Author details}

'Intensive Care Unit, Hospital Universitario de Getafe, Carretera de Toledo, km 12500, Getafe, 28905 Madrid, Spain. ${ }^{2}$ CIBERES, Instituto de Salud Carlos III, 28039, Madrid, Spain.

Published: 8 March 2011

\section{References}

1. de Groot RI, Dekkers OM, Herold IHF, de Jonge E, Arbous MS: Risk factors and outcome after unplanned extubations on the ICU: a case-control study. Crit Care 2011, 15:R19.

2. Whelan J, Simpson SQ, Levy H: Unplanned extubation: predictors of successful termination of mechanical ventilatory support. Chest 1994, 105:1808-1812.

3. Boulain T: Unplanned extubations in the adult intensive care unit: a prospective multicenter study: association des Reanimateurs du Centre-Ouest. Am J Respir Crit Care Med 1998, 157:1131-1137.

4. Atkins PM, Mion LC, Mendelson W, Palmer RM, Slomka J, Franko T: Characteristics and outcomes of patients who self-extubate from ventilatory support: a case-control study. Chest 1997, 112:1317-1323.

5. Krinsley JS, Barone JE: Unplanned extubation in the ICU. Chest 2005, 128:560-566.

6. Carrion MI, Ayuso D, Marcos M, Paz Robles M, de la Cal MA, Alia I, Esteban A: Accidental removal of endotracheal and nasogastric tubes and intravascular catheters. Crit Care Med 2000, 28:63-66.

7. Chevron V, Menard JF, Richard JC, Girault C, Leroy J, Bonmarchand G: Unplanned extubation: risk factors of development and predictive criteria for reintubation. Crit Care Med 1998, 26:1049-1053.

8. Chiang AA, Lee KC, Lee JC, Wei CH: Effectiveness of a continuous quality improvement program aiming to reduce unplanned extubation: a prospective study. Intensive Care Med 1996, 22:1269-1271.

9. Listello D, Sessler CN: Unplanned extubation: clinical predictors for reintubation. Chest 1994, 105:1496-1503.

10. Betbese AJ, Perez M, Ela B, Rialp G, Mancebo J: A prospective study of unplanned endotracheal extubation in intensive care unit patients. Crit Care Med 1998, 26:1180-1186.

11. Epstein SK, Nevins ML, Chung J: Effect of unplanned extubation on outcome of mechanical ventilation. Am J Respir Crit Care Med 2000, 161:1912-1916.

12. Epstein SK, Ciubotaru RL, Wong JB: Effect of failed extubation on the outcome of mechanical ventilation. Chest 1997, 112:186-192.

doi:10.1186/cc10049

Cite this article as: Peñuelas Ó, et al:: Unplanned extubation in the ICU: a marker of quality assurance of mechanical ventilation. Critical Care 2011, 15:128. 